\title{
Norms of Legitimate Dissensus
}

\section{CHRISTIAN KOCK University of Copenhagen}

\begin{abstract}
The paper calls for argumentation theory to learn from moral and political philosophy. Several thinkers in these fields help understand the occurrence of what we may call legitimate dissensus: enduring disagreement even between reasonable people arguing reasonably. It inevitably occurs over practical issues, e.g., issues of action rather than truth, because there will normally be legitimate arguments on both sides, and these will be incommensurable, i.e., they cannot be objectively weighed against each other. Accordingly, 'inference,' 'validity,' and 'sufficiency' are inapplicable notions. Further distinctive features of pro and con arguments in practical argumentation are explored, and some corollaries are drawn regarding evaluative norms of legitimate dissensus. Examples from immigrationrelated public debates in Denmark are given.
\end{abstract}

Résumé: Cet article propose que la théorie de l'argumentation pourrait profiter d'une connaissance approfondie de la philosophie morale et politique. Celle-ci explique l'existence du dissensus légitime, c'est-à-dire des désaccords persistant même entre les individus raisonnables qui argumentent raisonnablement. Dans l'argumentation pratique, c'est-à-dire s'agissant d'une action plutôt que de la verité, le dissensus légitime est inévitable parce qu'il y aura normalement, de tous les deux côtés, des arguments légitimes qui sont incommensurables (incapables d'être pesés objectivement les uns contre les autres). En conséquence, les notions d'inférence et de validité logique sont inapplicables. D'autres propriétés distinctives encore de l'argumentation pratique sont discutés, et des conséquences en sont tirés quant aux normes évaluatives du dissensus légitime. Des exemples sont discutés, tirés des débats publics au Danemark liés au sujet d'immigration.

Keywords: argumentation theory, moral philosophy, political philosophy, dissensus, consensus, legitimate dissensus, enduring dissensus, practical argumentation, Jürgen Habermas, Plato, Aristotle, John Rawls, Douglas Walton, logical dialogue games, burdens of reason, burdens of judgment, stasis system, Isaiah Berlin, Cicero, Walter SinnottArmstrong, Thomas Nagel, Trudy Govier, Charles Larmore, Michael Stocker, Joseph Raz, Carl Wellman, John Dryzek, immigration, Denmark, Georgia Warnke, Muhammad cartoons, Amy Guttman, Denis Thompson.

This paper makes a call for argumentation theory to open up towards disciplines such as moral and political philosophy. As argumentation scholars, we have much to learn from them and their emphasis on human action, whether it is seen as an individual or as a social phenomenon. They, on the other hand, have something to learn from scholars like us who scrutinize words, texts, and utterances to see how people use language to act. 
I suggest that, on the whole, contemporary argumentation theory is too narrowly allied to two branches of philosophy - logic and epistemology - to the neglect of those other disciplines which see humans as moral and political agents. This narrow perspective has allowed theorists in our field to work on the tacit assumption that argumentation is largely about how the truth of certain statements (called conclusions) may be inferred from the truth of other statements; and how people should proceed, when arguing over such matters.

\section{The two domains}

If argumentation theory would open up more towards moral and political philosophy, it would attain a widened perspective-one where not all argumentation is about whether statements are true, because some argumentation is about what to do.

These two categories of argumentation ought really, I suggest, to be seen as two separate domains. Aristotle saw them that way and named the two domains episteme and praxis. Also, as we shall see, he believed that argumentation in one of these domains is in many respects very different from argumentation in the other. To Plato, on the other hand, truth was the issue in any serious discussion, and he would have considered the Aristotelian distinction false. Unfortunately, modern argumentation theory has largely walked tacitly in Plato's footsteps in this respect, not in Aristotle's.

One of the perspectives that get left by the wayside when argumentation theory takes this line is what I call legitimate dissensus.

Now isn't that a near-tautology? After all, any discussion begins with dissensus; argumentation itself is based on it. So of course dissensus is legitimate. In the argumentation business it is our daily bread.

I am not talking about any kind of dissensus, though. The kind of dissensus I mean is the kind that will not go away, even after prolonged discussion. This kind of dissensus I call legitimate because it may not only exist but also endure. Even while using our best tools for the sake of common understanding, we do not reach consensus. At the end of our debate, we may still not have resolved our dispute, that is, we do not even agree as to who has won the argument; each of us may have played by the rules, yet there is no objective state of affairs as to the outcome of the game. Very likely we have also disagreed along the way as to the validity, or legitimacy, of some of the individual moves we have made.

By contrast, in a game like for example chess there can be no such dissensus. Either both players agree who has won, or both agree to call it a draw. Dissensus over the result of a chess game is just not chess. Board games are based on unanimity as to the legitimacy of the moves and the outcome of the game. A player who disputes the legitimacy of my moves or claims he has won when he is in fact checkmate is not being reasonable, and no one should play chess with such a person. For chess players to dissent on such matters is not legitimate. 


\section{The view of argumentation as analogous to chess}

Since Plato, it has been a prevalent idea among philosophers that when we discuss any matter, the discussion works the same way as in chess, or at least it should if we are reasonable. We may have a dispute at the beginning of the discussion, and we may both wish to prevail in it, but the idea is that we discuss by a set of rules that are agreed between us; that way we will always be in agreement as to the legitimacy of any move made by any of us, and we move from dissensus toward consensus in the sense that either I prevail, or you prevail, or we both agree to assume a third position; but whichever result ensues, none of us disputes it. In that sense we move hand-in-hand from dispute to its resolution.

Plato himself dramatized this method in many of his dialogues, most tellingly in the Meno, where Socrates questions a slave on how to construct a square twice as big as another square. Through their question-answer dialogue they come to the common understanding that the way to do it is not to draw a square with sides twice the length of the original one, but to use the diagonal of the original square as the side of the new one. And no one has questioned that insight since. In the Gorgias, Socrates describes the method explicitly by explaining that the two discussants are each other's only 'witnesses': “if on my part I fail to produce yourself as my one witness to confirm what I say, I consider I have achieved nothing of any account towards the matter of our discussion, whatever it may be; nor have you either, I conceive, unless I act alone as your one witness, and you nothing to do with all these others" (472b). "See therefore," he goes on, "if you will consent to be put to the proof in your turn by answering my questions" (474a).

The basic assumption here, and the basic warranty for the epistemic value of the method, is the same as the basic assumption in chess: both players agree on the rules, both agree on the legitimacy of each move, and hence both in consensus vouch for the outcome.

A similar view underlies the modern notion of "logical dialogue games." It has played an important role in the work of Douglas Walton (1984 and many other publications), and it underlies the idea of the "critical discussion" in PragmaDialectics (most recently codified in van Eemeren and Grootendorst 2004). In all of these conceptions - chess and other board games, the Platonic dialectic, logical dialogue games, and Pragma-dialectics—we find the same belief in commonly agreed rules securing unanimity as to the legitimacy of every move, resulting in a movement towards resolution of the original dispute, that is, consensus.

Outside of argumentation theory proper, there is yet another school of thought which has central notions in common with all these. The political philosophy of Jürgen Habermas and many who are inspired by him is centered around the ideal of a public discourse where participants obey 'den zwanglosen Zwang des besseren Arguments' ("the unforced force of the better argument") $(1972,161)$, reaching (or approximating) consensus along this road. 
However, Habermas, unlike Plato and unlike the pragma-dialecticians, explicitly recognizes important differences between the two domains of argument that we began with, those of episteme and praxis. Arguing about actions is not like arguing about the truth of propositions, in that the warrants we appeal to will not be other epistemic propositions we hold to be true, but norms of action that we hold to be 'right.' This rightness is a different kind of validity condition (Gültigkeitsbedingung) from the truth that validates constative (i.e., epistemic) speech acts; and these two are not the only types of speech acts with their specific types of validity conditions: both are different from the sincerity that validates expressive self-representations and from the adequacy of value standards that validates evaluative expressions.

Argumentation theorists might learn from the distinctions that Habermas lays down here. Nevertheless, as far as the main thrust of Habermas's argumentation theory is concerned, he joins the other thinkers who conceptualize argumentation as analogous to chess. Even though a proposal for action does make a distinctive kind of validity claim which is not truth, it is still, according to Habermas, just one form of a communicative practice which "is oriented to achieving, sustaining, and renewing consensus - and indeed a consensus that rests on the intersubjective recognition of criticizable validity claims" $(1997,17)$.

Central to all these conceptions is the idea that discussants in a dispute are, as it were, collaborators in a quest for consensus; they start from dissensus, but using regulated and reasonable discussion as their tool, they collaborate towards a common understanding, which may either be identical with what one of them began with, or an understanding new to both.

\section{The practical domain: enduring dissensus}

In opposition to all of these, my claim is precisely that because of the difference Habermas has seen (while the others, from Plato onwards, have either denied or underestimated it), namely the difference between epistemic and practical reasoning, we should understand that whereas consensus may be a meaningful theoretical ideal in the epistemic domain, it is not so in the domain of praxis. In the domain of praxis, enduring dissensus is inevitable and legitimate in a way that it is not in the epistemic domain, and it is high time that argumentation theory came to a full and unabashed understanding of this.

It is here that some of the leading figures in the moral and political philosophy of our time have something to teach us argumentation theorists. We may also have something to teach them about how people actually argue about such matters, and how it is still meaningful for them to so argue, even though it is legitimate for them to dissent. But we cannot teach them much about actual argumentation until we, on our part, have fully accepted their insight, namely that on practical issues people may find themselves in legitimate and enduring dissensus.

Now why is that? 
Perhaps the simplest way to answer that question is to say that practical issues are essentially about choice, not truth, and the possibility of choice entails the legitimacy of enduring dissensus. Aristotle said it succinctly in the Eudemian Ethics: "choice is not true or false" (1226a).

Another kind of answer to the question has been attempted by John Rawls (perhaps, with Habermas, the most influential political philosopher of our time). The way he states the question is interesting in itself: "Why does our sincere and conscientious attempt to reason with one another fail to lead us to agreement? It seems to lead to agreement in science, or if disagreement in social theory and economics often seems intractable, at least—in the long run-in natural science" $(1989,236)$. Notice that Rawls accepts the distinction between the epistemic and practical domains: in natural science consensus is, at least in the long run, an ideal and an actual achievement; in social theory and economics, given their evitable overlap with practical politics, it is less so, and in practical politics proper: not at all. Rawls disregards answers to the effect that people are driven by narrow interests or that they are irrational or stupid; that may be, but why do reasonable people, arguing reasonably about political issues, nevertheless disagree? If we assume, with Rawls, that they "share a common human reason, similar powers of thought and judgment, a capacity to draw inferences and to weigh evidence and to balance competing considerations," then what could the sources of disagreement be?

\section{The sources of disagreement}

Whatever the sources of disagreement between reasonable people are, Rawls calls them "the burdens of reason," or "the burdens of judgment" in the version appearing four years later in Political Liberalism (1993). His tentative list of them includes the following points (emphases are mine):

(a) The evidence - empirical and scientific — bearing on the case may be conflicting and complex, and hence hard to assess and evaluate.

(b) Even where we agree fully about the kinds of considerations that are relevant, we may disagree about their weight, and so arrive at different judgments.

(c) To some extent all of our concepts, not only our moral and political concepts, are vague and subject to hard cases; this indeterminacy means that we must rely on judgment and interpretation (and on judgments about interpretations) within some range (not itself sharply specifiable) wherein reasonable persons may differ.

(d) ... our total experience, our whole course of life up to now, shapes the way we assess evidence and weigh moral and political values, and our total experiences surely differ ... in a modern society ...the total experiences of citizens are disparate enough for their judgments to diverge. 
(e) Often there are different kinds of normative considerations of different force on both sides of a question and it is difficult to make an overall assessment.

(f) ... In being forced to select among cherished values, we face great difficulties in setting priorities, and other hard decisions that may seem to have no clear answer.

With all due respect for Rawls, I believe we may further reduce and arrange this list as follows.

(1) First on the list of sources of reasonable disagreement is still the complexity of evidence (a). This difficulty is found in epistemic as well as practical discussions.

(2) Second on the list I put the vagueness or disputability of the concepts we use to subsume the cases we discuss. This is (c).

(3) The third source of reasonable disagreement is the disputability of the weight we assign to relevant considerations. This is (b).

Looking at our revised list so far, anyone familiar with the history of rhetoric will perhaps recognize a reformulation of the ancient system of stasis or status (lucidly explained in Heath 1995). (1) corresponds to the conjectural status of fact. (2) is the definitional status: under what concept are we to subsume the fact? (3) is the qualitative status where we discuss the circumstances of the fact because they may influence the weight or gravity we assign to the fact.

Furthermore, it may be argued not only that the first three of Rawls's 'burdens of reason' match the three main status in ancient argumentation theory, but also that both these sets match the three types of evaluations criteria set up by many modern theorists, such as Govier's 'ARG' conditions as defined in her well-known textbook (2005, 63ff.): the acceptability condition, the relevance condition, and the good grounds condition. An argument is acceptable if we take it as referring to a fact; it is relevant if the concept it invokes is indeed instantiated by the matter at issue; and the judgment that is represents good grounds is an assessment of its weight or gravity.

As for Rawls's point (d), it actually is part of the empirical explanation of (b) and (c), so it is not a separate point in itself. Now for (e) and (f). Rawls remarks that the first four are not peculiar to reasoning about values $(1989,236)$, or as he says in the later version, they are "not peculiar to the reasonable and the rational in their moral and practical use" $(1993,56)$; but the last two — (e) and (f) —are. This is a crucial observation.

I suggest that (f) logically comes first. It means that our values may conflict. It is not just that two different individuals or groups in a society may believe in conflicting values; it is also that the set of values held by a given individual (as well as those values which are shared by practically everyone in the culture), may, on specific issues, contradict each other. The philosopher Isaiah Berlin has talked about the "pluralism" of values, meaning that "not all good things are compatible, 
still less all the ideals of mankind." For example, he points out "that neither political equality nor efficient organization nor social justice is compatible with more than a modicum of individual liberty, and certainly not with unrestricted laissez-faire; that justice and generosity, public and private loyalties, the demands of genius and the claims of society can conflict violently with each other" (1958; repr. 1998, 238).

Now this is something that ordinary human beings have always known in an intuitive way. Practical philosophers, such as Cicero, who was a rhetorician as well, have also known it. He writes:

between those very actions which are morally right, a conflict and comparison may frequently arise, as to which of two actions is morally better ... For, since all moral rectitude springs from four sources (one of which is prudence; the second, social instinct; the third, courage; the fourth, temperance), it is often necessary in deciding a question of duty that these virtues be weighed against one another (De Officiis 1.63.152).

\section{The moral philosophy of conflict}

The everyday reality of moral conflict between the values in which an individual or a social group believes has in our time been asserted by a wide range of moral philosophers. For example, Walter Sinnott-Armstrong (1988) has argued in depth that moral conflict is indeed possible, and Rawls himself cites Thomas Nagel (1979) for the view that "there are basic conflicts of value in which there seem to be decisive and sufficient (normative) reasons for two or more incompatible courses of action; and yet some decision must be made" (237, footnote 7).

To understand why this may be so, I believe we should look at item (e), where Rawls talks about "different kinds of normative considerations ... on both sides of a question" (237). The fact that considerations may be of different kinds is the reason why we often cannot just calculate which side has the stronger case. Cicero cites four different sources of moral rectitude; others might be added. Because they are qualitatively different, there is no intersubjective, algorithmic way of measuring them on the same scale. They are incommensurable. And we are not just talking about the sort of incommensurability first identified by the Pythagoreans, who found that, e.g., the side of a square and its diagonal are incommensurable. After all, side and diagonal have the same dimension: length; hence they are objectively comparable, and it is easy to demonstrate that the diagonal is longer than the side (cf. Stocker 1990, 176). Neither are we talking about situations like a business investment that has involved a certain cost and brought a certain return. Cost and return belong to the same dimension (money); deduct one from the other, and you have the net result: profit. But considerations involved in moral and other practical decisions often do not have 'lengths' that can be objectively compared, nor do they have objective 'weights,' although we often use that term about them; and they cannot be objectively converted into money.

Now this is the standard case when we consider the pros and cons of a practical decision. Here, a statement by Trudy Govier applies: "there is no formula or rule 
that we can apply to determine whether reasons for the conclusion outweigh reasons against it" $(2005,399)$, and in a footnote commenting on the term 'outweigh' she says: "No implication that we can mathematically measure or judge the relevance and comparative strength of various reasons or counterconsiderations is intended at this point" (415). When, for example, we discuss whether it is right to let a certain number of lives be sacrificed in an attempt to bring democracy to a foreign country, then the cost on one dimension is not as it were restored on the other dimension; instead a qualitatively different benefit is appealed to (cf. Stocker 1990, 272-277). We may refer to this circumstance as the irreducible multidimensionality of practical argumentation (Kock 2003). Because of this multidimensionality, profound incommensurability obtains; and that again is why a value conflict in an individual or a group committed to a plurality of values, as we all are, may have no intersubjective solution. The values involved are not, as the philosopher Charles Larmore has said, "rankable with respect to a common denominator of value" (Larmore 1996, 159). As a result, we cannot do what another moral and legal philosopher, John Finnis, describes in the following way: "Aggregate the pluses, subtract the minuses, and pursue the option with the highest balance" $(1998,216)$. That is, in deliberative argumentation there may be no objective or intersubjective way to determine which side outweighs the other.

\section{Incommensurability and choice}

Perhaps the most articulate contemporary interpreter of the notion of incommensurability is Joseph Raz. He defines the condition of two reasons for action being 'incommensurate' in the following way:

Two competing reasons (for specific actions on specific occasions) are incommensurate if and only if it is not true that one defeats the other, nor that they are of equal strength or stringency. They are incommensurate in strength, that is, reason does not determine which of them should be followed, not even that there is equal reason to follow either. When reasons are incommensurate, they are rendered optional, not because it is equally good (or right or reasonable) to choose the option supported by either reason, but because it is reasonable to choose either option (for both are supported by an undefeated reason) and it is not unreasonable or wrong to refrain from pursuing either option (for both are opposed by an undefeated reason) (2000, 102-103).

Raz believes in the everyday occurrence of incommensurate reasons and calls this belief a 'classical' stance, as against a 'rationalist' one. There are, according to Raz, three crucial differences between the two conceptions:

First, the rationalist conception regards reasons as requiring action, whereas the classical conception regards reasons as rendering options eligible. Second, the rationalist conception regards the agent's own desire as a reason, whereas the classical conception regards the will as an independent factor. Third, the classical conception presupposes the existence of widespread incommensurabilities of reasons for action, whereas the rationalist 
conception, if not committed to complete commensurability, is committed to the view that incommensurabilities are relatively rare anomalies. The three differences come down to a contrast between the rationalist view that generally rational choices and rational actions are determined by one's reasons or one's belief in reasons and are explained by them, as against the classical conception that regards typical choices and actions as determined by a will that is informed and constrained by reason but plays an autonomous role in action (2000, pp. 47-48).

In other words, 'rationalists' believe that the reasons for one action are necessarily stronger than those for another, and hence that they 'require' or 'determine' that action. Classicists, such as Raz and the other moral philosophers I have cited, and everyone in the classical rhetorical tradition, including myself, believe that on moral and other practical issues there is option or choice, or if you will, legitimate enduring dissensus, not just in practice but also in theory.

The important insight from moral philosophers has now been fully spelled out for us argumentation theorists, and it is time for us to offer some insights to them in return. The point is that after philosophers realize there is no required or determinable solution to a practical issue, they tend to conclude that there is no more to be said, so people will just have to plump for one or the other solution and shut up. This probably leaves many philosophers feeling slightly uneasy. After all, philosophers trade in general solutions to problems. Not that they dislike heated discussions of competing solutions, but usually the philosophical assumption is that if a solution to a problem holds, then it holds generally, that is, for all. On this view, if an issue is indeed optional, philosophical argument about it stops, as when Wittgenstein declared, in the concluding sentence of the Tractatus: "Wovon man nicht sprechen kann, darüber muß man schweigen" ["whereof one cannot speak, one must be consigned to silence"].

What we can teach philosophers, if indeed we understand it ourselves, is that even if there is no determinable philosophical solution to an issue, that does not mean that we cannot or should not argue about it. Although practical issues are in principle optional, not determinable, argument about them certainly goes on, and it should. Although an individual is free to choose on practical issues, that individual may change his mind, and he may be worked upon.

\section{Rhetoric as argument about choice}

The kind of argumentation through which we may work upon other individuals' free choice is rhetoric. The core of rhetoric is argumentation intended to work upon other individuals' choices regarding actions that they are free to undertake. This has been a given in the rhetorical tradition at least since Aristotle, who uses the verb bouleuein/bouleuesthai about the kind of reasoning that constitutes rhetoric. It is a word that we usually translate to 'deliberate' (which in itself means weighing on scales), and it is derived from boulê, a word with an original meaning of "will," etymologically related to the Latin volo and the English will. Aristotle repeatedly 
insists that what we may deliberate about is only actions we may choose to undertake. As he says in the Nichomachean Ethics, III: "any particular set of men deliberates about the things attainable by their own actions" (1112a). So rhetoric is debate about choosing action, and by the same token it is aimed at individuals and does not pretend to find solutions that are binding for all. (For a fuller statement of this, see Kock, in press.)

If a philosopher now asks, "But how can we argue about individual options?" the obvious answer is that the points where we can work rhetorically on individual choices are the same points where dissensus may arise in the first place: the sources of reasonable disagreement identified by Rawls and systematized earlier on in this paper. First, we may discuss facts. Secondly, the categories we use to subsume facts. And thirdly, matters of degree based on circumstances. But then, in the practical domain, where the issue is not what is true but what to do, we have two further complications: there may be conflict between equally relevant reasons on both sides, and they are not objectively commensurable. Recall that Rawls says these complications are "peculiar to reasoning about values" $(1989,236)$.

As a model example of deliberation by a collective body on a practical issue we may take the case of a family discussing the purchase of a large Chesterfield armchair. The parents, let us call them Dick and Jane, happen to agree that such a chair is comfortable, but also that it is somewhat inelegant, not to say ugly. So comfort and elegance are two value concepts shared by both Dick and Jane, but unfortunately they find that in this case these two value concepts conflict. Dick and Jane, too, are in conflict, because Dick values the chair's comfort so highly that he wants to buy it, while Jane finds its ugliness so prohibitive that she will have none of it. They have discussed the issue at length but find that there is no objective way for them to balance the comfort against the ugliness in a way they can both agree on. He finds that comfort trumps ugliness, she has it the other way around. We have a classic case of legitimate and enduring dissensus. This occurs because we are in the practical domain, and in that domain the issue is not about truth and facts, but on decisions based on values assigned to facts.

At this point, I cannot help citing one of my favorite examples of how people, when considering issues in the practical domain, may agree in principle that something has a positive value, yet their views may diverge widely as to just how great a positive value it has. In Jane Austen's Pride and Prejudice Mr. Collins, the unctuous clergyman, says, in proposing marriage to Elizabeth Bennet: "My situation in life, my connections with the family of De Bourgh, and my relationship to your own, are circumstances highly in my favour" (I, XIX). As we know, Elizabeth does not think these circumstances are as highly in his favour as all that.

\section{Distinctive features of practical argumentation}

These examples further show something that many argumentation scholars take to be rather scandalous, namely that at least as far as the 'weight' or 'strength' 
factor in practical reasoning is concerned, there is an ineradicable element of subjectivity in argument appraisal. To those who argue that the admission of such subjectivity is a disgrace to argumentation theory, and who call it 'extremely relativistic' and the like, I reply that their own theories are deficient for not seeing what moral philosophers since antiquity have seen, namely the inherent audiencerelativity of argumentation over issues where values are involved - as they are in any deliberative debate. In argumentation theory, Perelman \& Olbrechts-Tyteca (1958) were perhaps the first to fully understand this kind of subjectivity. The divergent 'value hierarchies' of audiences is one of the concepts in which they find this subjectivity expressed. It is the same subjectivity that is brought in by Rawls's last two points, which, let us recall again, are "peculiar to reasoning about values."

Our examples also show that pro and con arguments in the practical domain typically have the status of advantages and drawbacks, as perceived by the arguers. Dick and Jane happen to agree on all the advantages and drawbacks of the armchair. For both of them, those advantages and drawbacks are inherent in the chair. But Dick and Jane disagree on how much weight to assign to them. And no advantages or drawbacks are refuted, rebutted or defeated even if either Dick or Jane prevails. Even if the armchair scheme is abandoned, an armchair like this does not cease to be comfortable. If the family actually buys the chair, it remains inelegant.

In the epistemic domain, by contrast, pro and con arguments are only important by virtue of their probative or inferential force (or, with a word used by some theorists and derived from the same verb as "inferential": their illative force); that is, they are important for what they appear to signify or suggest, not for what they are. Once the issue has been decided one way or the other, the arguments supporting the discarded position lose their relevance.

The example of the armchair further shows that in the practical domain pro and con arguments may be real and relevant simultaneously. The advantages and drawbacks are real to the arguers and remain so. In epistemic argumentation, on the other hand, the pro and con arguments may in themselves be real enough, but the two opposite states of affairs signified by the pro and con arguments, respectively, may not both be real or true simultaneously.

Further, the strength or weight of arguments in practical argumentation is a matter of degrees. Advantages and drawbacks come in all sizes. Along with this comes the fact that practical argumentation typically persuades by degrees. An individual may gradually come to attribute more weight to a given argument, so he or she may gradually become more favorably disposed towards the proposal. This is one of the reasons why argument in matters of choice is meaningful.

Finally, let us repeat that practical reasoning crucially depends on individuals' subjective value assignment. That goes for each single reason given in the discussion of the issue, but also for the balancing of the multiple, incommensurable reasons relevant to the case. 
The type of argumentation described here is really a branch of Carl Wellman's 'conductive reasoning' (1971). Govier among others has adopted this term, but she does not distinguish, as I insist on doing, between arguments in the epistemic and the practical domain. What I have just been describing is practical reasoning. All practical reasoning is conductive, but not all conductive reasoning is practical.

\section{Norms in practical argumentation}

Now that we have established practical reasoning as a separate domain of argumentation with particular properties, we may ask: What norms may we appropriately apply in this kind of argumentation?

First, we may conclude that as criteria in argument evaluation, the notions of validity, inference, sufficiency all have to go; no arguments for or against actions have any of these properties. No party, when arguing for or against a practical proposal, can be logically proven to be either right or wrong. In principle, arguments in the practical domain can never be 'valid' in the sense of entailing their conclusion. No matter how many arguments you muster for your proposal, your opponent is never compelled by those arguments to accept it. This is because, as we have seen, the practical domain is one of choice.

It is worth emphasizing that the terms 'sufficiency' or 'adequacy' are no change or improvement on the traditional 'validity' requirement. If 'sufficiency' is to have a clear meaning, it must mean, as in mathematics, that there is inference. And inference, in a nutshell, is the negation of choice.

Furthermore, since even reasonable people arguing reasonably cannot be expected to reach consensus, we may conclude that a set of norms that posits eventual consensus as the goal of reasonable discussion, such as the argumentation theories of Habermas or Pragma-Dialectics, is not applicable to practical reasoning.

But if consensus is not the goal of discussion, and if it may even be legitimate for discussants to remain fully committed to their initial standpoints, then a set of norms should perhaps be more concerned with what discussion can do for the audience.

The function of practical argumentation for its audience would more meaningfully be defined in terms of the enlightenment it might provide, i.e., the extent to which it equips the audience to make up their own minds on the issue. Since argumentation in the practical domain is never compelling, and since inference does not exist, and since the audience's needs are central, it seems reasonable that such argumentation should not be required to provide an inference to the proposal or policy it argues for, but rather to supply explicit and relevant informative reasons at any point of dispute.

Also, since there will usually be several relevant reasons and counterconsiderations, belonging to different dimensions, it becomes essential that debaters should, in the metaphorical sense, weigh those reasons and considerations up against each other. 'Weighing' here does not mean 'measuring,' because there 
is no such thing, but it does mean 'comparing.' Each debater must use the resources of rhetoric somehow to hold the multidimensional pros and cons together, making a bid as to his or her own individual assessment of how they compare and balance, and giving audience members added input to make their own individual assessments.

From these principles we might derive rules such as the following:

For any point where dissensus exists, debaters must give reasons. This goes not only for the proposal or policy for which a debater ultimately argues, but also for each argument given at a lower place in the argument hierarchy. More specifically, this implies that if a debater does not recognize the acceptability, relevance or weight of one of the opponent's arguments, he must give reasons for this nonrecognition. Similarly, if a debater does not want an objection to one of his arguments to stand, he must give reasons why it does not stand.

We should note at this point that recognizing an argument given by the opponent does not mean that acceptance of his proposal or policy can be inferred, because, as we have seen, in the practical domain there is no such thing as inference. This is worth emphasizing, since political debaters often seem compulsively to deny each and every argument given by opponents, apparently for fear that if they did concede the relevance of any point made by them, they would be compelled by inference to accept their proposal or policy. This kind of behavior polarizes and distorts public debate, and it goes to show how mistaken it is to think of practical argumentation in terms of inference.

The explicitness principle, turned into a negative, further implies that on any point where dissensus exists, a debater should not implicitly assume his or her own view to be generally accepted. This sounds obvious, but this type of behavior accounts for many of the 'spin' maneuvers and other misdemeanors we find in political debate. Discussions of issues such as abortion, taxation, or terrorism are full of linguistic maneuvers in which a view or assumption that part of the audience contests is taken for granted by means of framing language, presupposition, conversational implicature, and the like. On all such points, argumentation scholars should insist that any assumption on which there is dissensus should be made explicit and supported by reasons. And the same principle also dictates that any reasons given by opponents should be answered - either rebutted or acknowledged, and if acknowledged, compared and 'weighed,' since we know that in the standard case, there are non-rebuttable reasons on both sides.

All in all, in this revised set of norms for legitimate dissensus answering becomes essential. Because advantages and drawbacks are properties of the proposal they relate to, not just signifiers, and hence do not go away, there will, in the standard case, be relevant counterconsiderations. So, to recall the armchair example, an appropriate answer from Jane to Dick's argument that a Chesterfield chair is comfortable is not to deny this fact or its relevance to the issue, but to explain why, in Jane's view, this property is outweighed by the chair's negative value on another dimension, that of elegance. Jane can never not prove to Dick or to the audience, which in this case means Dick and Jane's teenage kids, Ethan and Chelsea, 
that this is so; consequently, Jane must try to make them see it. She will have to use rhetoric to win their support of the way she balances the incompatible and incommensurable values involved in the issue. She might not be able to win over Dick himself, but Ethan and/or Chelsea might eventually come down on her side, and that might settle the issue. What she should not do, either for her own sake or in the light of reasonable norms of legitimate dissensus, is to flatly deny or ignore the argument that the chair is comfortable. For audience members who considers both comfort and elegance to be relevant, and who need input to help them decide for themselves which is weightier, such a reply would be no help at all.

\section{Meta-consensus, not consensus}

The Australian political scientist John Dryzek is among those who deny that consensus is the reasonable theoretical endpoint of deliberative debates. Instead he has introduced the concept of meta-consensus. As we have done here, he sees deliberative debate as having three levels: that of normative values, that of epistemic beliefs ("facts"), and based on these two, that of preferences regarding action. Dryzek, writing with Simon Niemeyer, defines normative meta-consensus as "agreement on recognition of the legitimacy of a value, though not extending to agreement on which of two or more values ought to receive priority in a given decision" (Dryzek \& Niemeyer 2006, 639; the term 'normative meta-consensus' corresponds to 'axiological consensus' in Rescher 1993). One norm of argumentation in the case of enduring dissensus is that a debater should recognize the legitimacy of a value to which his opponent appeals if he himself shares that value, even when he disagrees on its relative priority. Dick and Jane did this on the armchair issue. Dryzek also notes that "adversarial processes (such as AngloAmerican legal systems) may weaken normative meta-consensus if they frame issues in ways that induce advocates to denigrate the legitimacy of the values of the other side." He suggests that "one of the main tasks of deliberation could be to uncover existing normative meta-consensus obscured by the strategic actions of partisans who try to de-legitimate the values held by their opponents" $(2006,639)$.

\section{Norm-flouting argumentation: immigration-related debates in Denmark}

The debate that has been going on for the last twenty years or so in my own country, Denmark, about issues relating to immigration and immigrants, abound in argumentation flouting this norm. One controversial issue has been the legislation introduced by the current right-wing government on the residence in Denmark of couples where one spouse is a Danish national and the other is not. Among other things, both spouses must be at least 24; there are income, housing and employment requirements; and the combined 'attachment' of the spouses to Denmark must be greater than their attachment to any other country. Supporters of these rules have argued that they help integration by preventing forced or arranged marriages between 
nationalized immigrants and individuals from their country of origin. Opponents have argued that these rules curtail personal freedom, including citizens' rights to live in their home country with spouses of their choice.

On the whole, opponents of this law have tended to focus single-mindedly on these values and have rarely addressed the law's alleged social benefits, including its presumed effects against forced marriages - a consideration that has made a certain number of immigrant women support the law. I would argue that while argumentation theory could not expect or require opponents on such an issue to reach consensus, they should not behave as if one principle might decide the issue, as it were, by inference; instead they should recognize the relevance of the alleged social benefits appealed to by the other side. We might add that arguably personal freedom is involved on both sides of the issue: on the one hand, the law curtails people's freedom of marriage and/or residence, but on the other hand the argument is that the law extends young people's freedom to avoid forced marriages. So what one might expect from the law's opponents is that they explain why, in their view, these alleged advantages are outweighed by the rather obvious drawback of curtailing certain personal freedoms.

To provide such an explanation, opponents might spell out the effects of these curtailments based on specific examples, either authentic or devised; or they might seek to reduce the perceived benefits of the law by using statistics to show that forced marriages are a small or a dwindling problem; or they might make a pathosbased attempt to heighten the perceived weight of individual freedom as principle; or they might analogize to other cases of freedom-curtailing legislation that most people would agree to condemn; or they might try to show that the legislation will create more social ills than benefits and in effect counteract integration. In short, they might use any and all of the resources of rhetoric to help them compare the weights of the pros and cons. Indeed, rhetorical resources are all we have to help us compare those weights and decide on the issue, since they cannot be weighed, measured or calculated in any objective way. But compare them we must.

We might add to this that such a meta-consensus might be called for, not only where debaters disagree on the priorities of values in a given case, but also when they disagree on their very relevance to that case. The notorious affair of the Muhammad cartoons which a Danish daily published on September 30, 2005, and which, the following winter, caused a political crisis in Denmark and serious unrest with deaths and destruction in many Muslim countries, is a case in point. In Denmark, one side in the debate that ensued held that freedom of speech was at issue, while the other held that interpersonal respect was at issue. However, the issue separating the two opposed factions in the Danish debate was not, as they should both have recognized, their commitment to the value of freedom of expression, but their interpretation of the specific events of the affair.

A similar view, highlighting the role of interpretation in apparently intractable conflicts, has been argued by the philosopher Georgia Warnke in Legitimate Differences (1999). Since the dispute in Denmark was not really over principles 
and values, but over the interpretation of the cartoons in relation to those values, the debate ought to have been about that interpretation, not about whether certain people had betrayed the cause of freedom of expression. But the supporters of the cartoons, on the whole, did not enter into debate about their view that the publication of them was indeed a matter of defending freedom of expression. Rather they argued in a way that took this contested interpretation for granted. This they did using linguistic mechanisms such as framing, presupposition, implicature, etc. Instead, their strategy was to say that those who had criticized the cartoons or failed to lend the newspaper their whole-hearted support, for example by refusing to reprint them, were to be roundly condemned for betraying freedom of expression. On February 26, 2006, Prime Minister Fogh Rasmussen said in an interview with a national daily: "Writers and others, who so much live by the freedom of expression, have, as you know, failed in this matter. ... As far as I am concerned, the sheep have been separated from the goats." Thus the pro-cartoon faction, led by the Prime Minister, illegitimately took their interpretation for granted instead of defending it; but the faction that was critical of the cartoons, in its insistence that the matter had nothing to do with freedom of expression, but instead with lack of proper respect for religious minorities, perhaps did not sufficiently articulate their shared allegiance to freedom of expression and their concern that certain tendencies in Muslim populations were in fact a threat to that freedom. The reason for this was presumably their view that freedom of expression was not relevant to the case at all, since they had not questioned the newspaper's right to print the cartoons. Yet they might have helped bring about a meta-consensus by admitting that the situation seen in a broader perspective clearly did make freedom of expression an important concern.

What happened subsequently in the Danish debate was a predictable orgy of name-calling. The pro-cartoon debaters in particular were uninhibited in taking their own contested interpretation as a given even though they must have known that their opponents did not acknowledge it—a maneuver that has been described as linguistic "bullying" (Harder \& Kock 1976). Both factions in the heat of the squabble thrashed away at obvious straw men. For example, a past Minister of Foreign Affairs who had from the beginning been critical of the newspaper's publication of the cartoons was accused, by implicature, of advocating groveling surrender to the violent protesters in the Middle East. The whole debate showed all the symptoms of pernicious and pointless polarization. The diagnosis: no one made the attempt to find any kind of normative meta-consensus, on the basis of which there could have been a reasoned and explicit discussion of the interpretations and weightings over which debaters were actually, and legitimately, in dissensus.

\section{Agreement on how to disagree?}

For some appropriate concluding remarks to these reflections on norms of legitimate dissensus we might again turn to John Rawls. His listing of the sources of reasonable 
disagreement leads to what he calls "precepts of reasonable discussion." They are, in slightly abbreviated form:

First, the political discussion aims to reach reasonable agreement, and hence so far as possible should be conducted to serve that aim. We should not readily accuse one another of self- or group-interest, prejudice or bias, and of such deeply entrenched errors as ideological blindness and delusion.

Second, when we are reasonable we are prepared to find substantive and even intractable disagreements on basic questions. ...

Third, when we are reasonable, we are ready to enter discussion crediting others with a certain good faith. We expect deep differences of opinion, and accept this diversity as the normal state of the public culture of a democratic society $(1989,238-239)$.

Another way of stating the same desiderata is to say, with Amy Gutmann and Denis Thompson in Why Deliberative Democracy?, that we need norms of dissensus "which permit greater moral disagreement about policy and greater moral agreement on how to disagree about policy" $(2004,65)$.

\section{References}

Aristotle. The Rhetoric.

Aristotle. The Eudemian Ethics.

Aristotle. The Nichomachean Ethics.

Cicero. De Officiis.

Dryzek, J.S., \& Niemeyer, S.J. (2006). Reconciling pluralism and consensus as political ideals. American Journal of Political Science, 50, 634-49.

van Eemeren, F.J., \& Grootendorst, R. (2004). A systematic theory of argumentation: The pragma-dialectical approach. New York : Cambridge University Press.

Finnis, J. (1998). Commensuration and public reason. In Incommensurability, incomparability, and practical reason, ed. Ruth Chang. Cambridge, Mass.: Harvard University Press, 215-233.

Govier. T. (2004). A practical study of argument. $6^{\text {th }}$ ed. Belmont, CA. : Wadsworth.

Gutmann, A., \& Thompson, D. (1990). Moral conflict and political consensus. Ethics 101, 64-88. Reprinted in Liberalism and the good, ed. R. Bruce Douglass, Gerald Mara, and Henry Richardson. New York: Routledge, 125-47.

Gutmann, A., \& Thompson, D. (2004). Why deliberative democracy? Princeton: Princeton University Press.

Habermas, J. (1972). Wahrheitstheorien. In Vorstudien und Ergänzungen zur Theorie des kommunikativen Handelns. Frankfurt/M.: Suhrkamp, 127-183.

Habermas, J. (1997). The theory of communicative action. Vol. 1: Reason and the rationalization of society. Translated by Thomas McCarthy. Cambridge: Polity Press. (Original: Die Theorie des kommunikativen Handelns, Band I: Handlungsrationalität und gesellschaftliche Rationalisierung. Franfurt: Suhrkamp, 1981.) 
Harder, P., \& Kock, C. (1976). The theory of presupposition failure. (Travaux du Cercle Linguistique de copenhague, XVII.) Copenhagen (Akademisk Forlag).

Heath, M. (1995). Hermogenes on issue: Strategies of argument in later greek rhetoric. Oxford : Clarendon Press.

Kock, C. (2003b). Multidimensionality and non-deductiveness in deliberative argumentation". In van Eemeren, F.H. Anyone who has a view: Theoretical contributions to the study of argumentation (pp. 157-171). Dordrecht: Kluwer.

Kock, C. (In press.) The domain of rhetorical argumentation. Proceedings of the 6th ISSA conference.

Larmore, C. (1996). The morals of modernity. Cambridge: Cambridge:University Press.

Nagel, T. (1979). Mortal questions. Cambridg: Cambridge University Press.

Perelman, C., \& Olbrechts-Tyteca, L. (1958). La nouvelle rhétorique: traité de l'argumentation. Paris: Presses Universitaires de France. (American edition, transl. by John Wilkinson and Purcell Weaver: The new rhetoric: A treatise on argumentation. Notre Dame, IN: University of Notre Dame Press, 1969.)

Plato. Gorgias.

Plato. Menon.

Rawls, J. (1989). The domain of the political and overlapping consensus. New York University Law Review 64, 233-255.

Rawls, J. (1993). Political Liberalism. New York: Columbia University Press.

Raz, J. (1998). Incommensurability and agency. In Chang, R. (Ed.), Incommensurability, incomparability, and practical reason. Cambridge, Mass.: Harvard University Press, $110-128$.

Raz, J. (2000). Engaging reason: On the theory of value and action. Oxford: Oxford University Press.

Rescher, N. (1993). Pluralism: Against the demand for consensus. Oxford: Clarendon Press.

Sinnott-Armstrong, W. (1988). Moral dilemmas. Oxford: Basil Blackwell.

Stocker, M. (1990). Plural and conflicting values. Oxford: Oxford University Press.

Walton, D.N. (1984). Logical dialogue-games and fallacies. Lanham, Maryland: University Press of America.

Warnke, G. (1999). Legitimate differences: Interpretation in the abortion controversy and other public debates. Berkeley: University of California Press.

Wellman, C. (1971). Challenge and response: Justification in ethics. Carbonale, IL: Southern Illinois University Press.

Christian Kock

Department of Media, Cognition and Communication

University of Copenhagen

Njalsgade 80

2300 Copenhagen $S$

Denmark

kock@hum.ku.dk 